\title{
Glossa
}

a journal of general linguistics

\section{Revisiting subjunctive obviation in French: a formal acceptability judgment study}

\section{INGO FELDHAUSEN (D)}

\section{SEBASTIAN BUCHCZYK (1D}

*Author affiliations can be found in the back matter of this article

\begin{abstract}
Even though the weakening of the subjunctive disjoint reference effect, also known as obviation, plays an important role in the research of subjunctives in (non-)Romance languages, to the best of our knowledge it has never been verified experimentally. The goal of our paper is to test how native speakers of (European) French evaluate sentences displaying factors that (according to Ruwet 1991) should weaken obviation using a formal acceptability judgment task. Our results show that we were unable to replicate Ruwet's observations (when averaging over multiple participants): only one out of six factors described by Ruwet seems to clearly weaken obviation, namely Coordination. We conclude that (a) French may be a language for which formal experimentation of complex data is useful, (b) idiolects should not be ignored, and (c) our results challenge theoretical accounts of obviation weakening. Finally, we relate our study to the ongoing discussion on whether informal methods of collecting acceptability judgments (such as introspection by the author) need to be verified by formal methods.
\end{abstract}

\section{CORRESPONDING AUTHOR:}

\section{Ingo Feldhausen}

ATILF-CNRS \& Université de Lorraine, 44, Avenue de la Libération, 54000 Nancy, FR ingo.feldhausen@univlorraine.fr

\section{KEYWORDS:}

French; mood; subjunctive; disjoint reference; obviation weakening; reliability; acceptability judgment; formal method

TO CITE THIS ARTICLE: Feldhausen, Ingo and Sebastian Buchczyk. 2021. Revisiting subjunctive obviation in French: a formal acceptability judgment study. Glossa: a journal of general linguistics 6(1): 59. 1-14. DOI: https://doi.org/10.5334/ gjgl.1219 


\section{Introduction}

One of the primary sources of data in linguistics are acceptability judgments (cf. Chomsky 1965: ch.1; Newmeyer 1983: ch.2; Sprouse et al. 2013). Acceptability judgments can be obtained through different methods, with Sprouse et al. (2013: 224) classifying them into informal and formal methods. Informal methods are characterized by the involvement of relatively few (expert) participants (most often the author of a given paper), by relatively few tokens per condition, and by relatively little explicit instruction. The opposite picture characterizes formal methods: many non-expert, naive participants, several tokens per condition, explicit instruction, most often a statistical analysis, and many more response options.

In this paper, we revisit the seminal study by Ruwet (1991 [1984]), in which he presents introspective acceptability judgments on subjunctive obviation in European French, suggesting that obviation can be weakened under certain conditions (see $\S 2$ and $\S 3$ for examples). This phenomenon has never been approached using a formal method in French (or any other language) to the best of our knowledge. We revisit his data and test how robust his results are by using a formal acceptability judgment method. Our results indicate that we cannot entirely replicate Ruwet's observations. The conclusions we draw from this are as follows:

(a) French appears to be a language for which formal experimentation of complex data is useful.

(b) Even though we found little evidence for obviation weakening, our results do not call the phenomenon of obviation weakening itself into question because (i) we only considered a subset of possible cases (see §2 and §3) and (ii) few individuals show a pattern similar to the one by Ruwet (1991).

(c) If we are on the right track, our results have clear consequences for theories on obviation weakening.

(d) Additional data must be considered, and additional experimental methods must be carried out to obtain a better overall picture of possible obviation weakening (in French).

The paper is structured as follows: In $\S 2$, we present the basic tenets of subjunctive obviation in French before we introduce obviation weakening and Ruwet's factors in $\S 3$. The acceptability judgment task and its results are presented in $\S 4$ and discussed in $\S 5$.

\section{Subjunctive obviation in French}

The subjunctive is a verbal mood in French (cf. Gsell \& Wandruszka 1986; Le Goffic 1993: 122ff.; De Mulder 2010; Riegel et al 2014: §X.2.2; Mosegaard Hansen 2016: §5.4., among others). Following Quer (2020: 6), subjunctives consistently appear when the speaker conveys a meaning related to uncertainty or counterfactuality, which raises the question of how to assess such meaning on a theoretical level. Most semanticists relate subjunctive mood to the domain of modality and conversational context (Farkas 1992; Giannakidou 1997, 2009; Giorgi \& Pianesi 1997; Portner 1997; Quer 1998, 2001; Schlenker 2005). However, there are still debates as to whether such approaches apply to all occurrences of the subjunctive (Quer 2020: $23 \mathrm{f}$.), which gives reason to question whether the subjunctive mood should be treated as a universal semantic category as such (see Wiltschko 2016).

Independent of this ongoing discussion, the fundamental issue for our study is that the subjunctive expresses a disjoint reference between the subject of the matrix clause and the subject of the complement subjunctive clause, cf. (1).

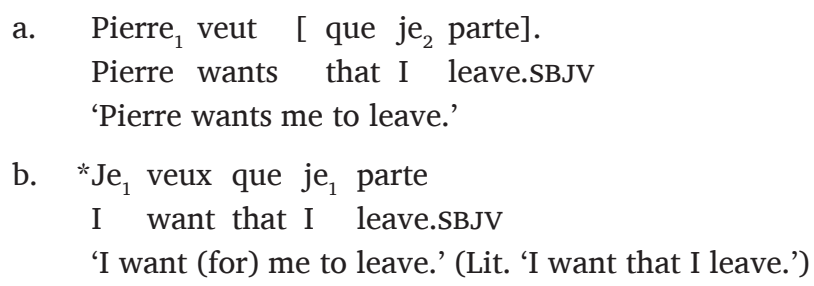

Feldhausen and Buchczyk

Glossa: a journal of

general linguistics

DOI: $10.5334 /$ gjgl.1219

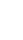

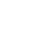


This phenomenon is known as the subjunctive disjoint reference effect or obviation ${ }^{1}$ (i.a. Picallo 1985; Kempchinsky 1987, 2009; Farkas 1992). For coreferential subjects, in turn, the infinitive is used, (2).

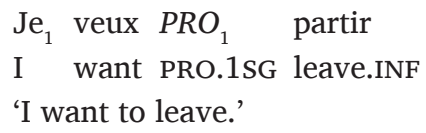

The phenomenon of obviation has long been known, with a vast body of literature discussing it in detail for different languages such as French, Spanish, Catalan, Italian, Hungarian, Russian, and Polish (e.g. Bouchard 1983, 1984; Ruwet 1991 [1984]; Raposo 1985; Picallo 1985; Suñer 1986; Farkas 1992; Costantini 2005, 2009, 2013, 2016; Schlenker 2005; Feldhausen 2007, 2010: 140ff.; Szucsich 2009; Quer 2017, and others). Quer (1998), for example, observes that obviation is a phenomenon that occurs only in a subset of subjunctive types (contra Picallo 1985), namely intensional subjunctives, ${ }^{2}$ i.e. subjunctive clauses that appear in the scope of intensional elements such as verbs of volition or command (Quer 2016: 957, but see also Costantini 2009: 21 for the relationship between obviation and other types of subjunctives in Italian). In the following, we adopt Quer's (1998) line of reasoning here and focus in particular on complements of vouloir 'want', an intensional verb.

\section{Obviation weakening}

\subsection{Concept}

Despite the clear distribution in (1) and (2), several authors show that obviation can be weakened so that a coreferential reading with subjunctive complements becomes available (Ruwet 1991 [1984]; Raposo 1985; Kempchinsky 1987; Farkas 1992; Costantini 2009, 2016; Feldhausen 2010: 140ff., and many others). Ruwet (1991 [1984]) was one of the first to demonstrate and discuss obviation weakening. An example is given in (3), where the weakening is indicated by '?'; the sentence is neither ungrammatical nor grammatical. According to Ruwet, several factors weaken obviation (see §3.2).
(Ruwet 1991: 20)
?Je veux que je sois autorisé à partir demain.
I want that I am.SBJV authorized to leave.INF tomorrow
'I want for me to be allowed to leave tomorrow.'

Beginning with the pioneering work of Ruwet (1991 [1984]), obviation weakening has played an essential role in research on subjunctives and in linguistic theorizing (see, e.g., Costantini 2005, 2009; Quer 2017 for an overview). Our review of the literature reveals that the provided data either stem mainly from introspection on the part of the authors (e.g. Ruwet 1991; Costantini 2009) or are adapted from the literature (e.g. Suñer 1986; Farkas 1992; Quer 2017). ${ }^{3}$ To address the lack of formal experimentation, we developed the research question in (4) concerning the robustness of claims regarding obviation weakening made by Ruwet (1991). Since his work is fundamental to our understanding of obviation weakening, we concentrated on his factors and on European French.

(4) Can we replicate Ruwet's (1991) results on obviation weakening by using a formal acceptability judgment method?

\footnotetext{
1 The term 'obviation' was originally used in describing a grammatical category of Algonquian languages (North America; see Cuoq 1866 and Mithun 1999). Later, it was adopted for the subjunctive disjoint reference effect.

2 Building on Stowell (1993), Quer (1998) proposes a categorization of subjunctives into two basic classes or types, namely intensional (sometimes referred to as 'volitional' or 'optative'), and polarity ('potential' or 'dubitative') subjunctives. Along with these two, Quer (2016) also lists 'thematic' or 'factive' subjunctives as a third class (see also Gsell \& Wandruszka 1986).

3 It is noteworthy here that Poplack (1992: 237) found some instances of coreference in her sociolinguistic interviews with native speakers of Canadian French. Since we concentrate on European French and do not investigate mood choice variability, we merely wish to mention her findings at this point.
} 


\subsection{Ruwet's (1991 [1984]) factors of obviation weakening}

Focusing on French, Ruwet (1991) argues that coreferential reading improves under specific circumstances by:

(i) reducing the agentivity of the subject (p. 20) and

(ii) creating a distance between the expression of desire and the fulfillment of the action (p. 21).

If these two aspects hold true in an embedded subjunctive, obviation is weakened, and coreference becomes more acceptable. After presenting this general idea, Ruwet (1991) discusses several individual factors which lead to a weakening of obviation; we will focus on six of them. Before presenting them in detail, a note on the indicated judgments in this section is necessary: the judgments are those found in Ruwet (1991). As far as we can tell, most of the judgments seem to be his own, though he occasionally took examples from others. We do not know (a) how many tokens were tested per condition (though we assume only the tokens presented in his paper) or (b) how many response options were available (we assume the classical division of $O K$, ? and *, though he also uses ??). No statistical analysis was conducted in the original work. Thus, Ruwet (1991 [1984]) applied a classical informal method (see §1).

Passive: In (5a) and (5b), the verbal form of the subjunctive complement is in the passive voice. While (5a) is better than (1b), it is worse than (5b). Ruwet (1991) argues that the passive voice per definitionem does not express an action of the subject, thus resulting in a reduction of agentivity. The fulfilment of the speaker's will must in some way "make a detour and pass by way of someone else's will" (p. 20). Moreover, the semantics of the embedded verb may affect the acceptability judgment: enterrer 'bury' suggests that the speaker is no longer present to guarantee the completion of their will (p. 20).

(5)

(Ruwet 1991: 20)
a. ?Je veux que je sois enterré dans mon village natal.
I want that I am.SBJV buried in my village native
'I want for me to be buried in the village of my birth.'
b. Je veux être enterré dans mon village natal.
I want be buried in my village native
'I want to be buried in the village of my birth.'

Periphrastic past: According to Ruwet (1991: 23), any element that tends to imply a distance between the will and the accomplishment of the corresponding act is likely to improve acceptability (see (ii)); it can thus be enough to put the subjunctive clause in the perfective aspect, emphasizing the accomplishment of the act (6).

(6)

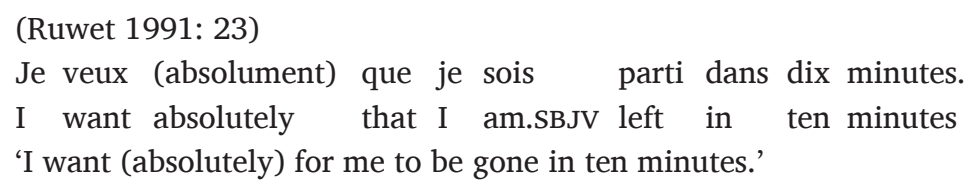

Negation: Ruwet (1991: 29) further shows that if the matrix verb is negated and the embedded clause includes a more or less negative expression with respect to the subject, the whole sentence becomes more acceptable, (7). The speaker expresses their desire for an event not to happen again but cannot fully influence the future outcome (see (ii)).

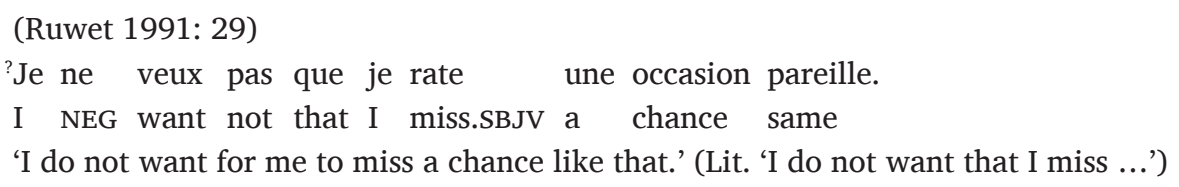

Modals: In (8), the modal verb pouvoir 'can' is in the complement clauses. The subjunctive form in (8a) is less acceptable than the infinitive in (8b). However, according to Ruwet (1991: 21 ), the acceptability of (8a) depends on the context: (8a) would appear more natural if a businesswoman were addressing her secretary, asking her to book a reservation for a flight (see (ii)). 
a. ?Je veux que je puisse partir dès demain.

'I want for me to be able to leave (by) tomorrow.'

b. Je veux pouvoir partir dès demain.

I want can.INF leave from tomorrow

'I want to be able to leave (by) tomorrow.'

Psych-verbs: For Ruwet (1991: 27), sentences such as (9) with a psych-verb in the embedded clause are only acceptable if they are interpreted as non-agentive (see (i)). In his interpretation, the presence of the embedded subject causes the speaker to imagine a second instance of themselves observing the act from afar.

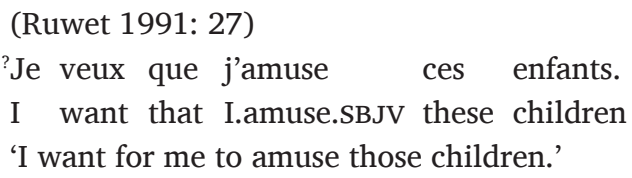

Coordination: In (10), the embedded clauses consist of two conjuncts. The difference between (10a) and (10b) is the order of the subjects in the conjuncts (je 'I' + tu 'you' in (10a), tu 'you' + je 'I' in (10b)). As stated by Ruwet (1991: 24), the respective order is highly relevant. The matrix subject is je 'I'. (10a) is ungrammatical because the conjunct with the coreferential subject immediately follows the matrix verb (order of subjects: je-je-tu). (10b), on the other hand, is better because the conjunct with the coreferential subject remains distant from the matrix verb (je-tu-je). Whereas the previous factors are all based on semantic interpretation, this factor is purely syntactic.

(Ruwet 1991: 24)

a. *Je veux que je parte et que tu restes.

I want that I leave.SBJV and that you stay.SBJV

'I want for me to go and for you to stay.' (Lit. 'I want that I leave and that you stay.')

b. ?Je veux que tu partes et que je reste.

I want that you leave.SBJV and that I stay.SBJV

'I want for you to leave and for me to stay.'

\section{Experimental study}

\subsection{Methodology}

\subsubsection{Participants}

A total of 88 French native speakers (21 males, 64 females, and three non-specified) completed our online survey. We had to exclude one speaker. ${ }^{4}$ The participants ranged from 18-76 years of age. They were either enrolled at university, employed or pensioned. Only four participants held a degree below A levels ("baccalauréat") at the time of the study. We included a short practice session at the beginning of the experiment with items that we did not analyze.

\subsubsection{Material and design}

The study was carried out using a formal acceptability judgment method (cf. Featherston 2006; Sprouse et al. 2013; Sprouse 2018). Our survey was comprised of 96 items: 48 test items (six factors $\times$ eight lexicalizations of each factor) and 48 filler clauses (out of which we chose 15 items as "control fillers"). The test items consisted of the original sentences from Ruwet (1991) and newly created lexicalizations (see Appendix). The items were pseudo-randomized (sentences of the same factor never appeared immediately after one another). Each item was displayed separately, followed by the Likert-type-7 scale (Schütze \& Sprouse 2013) below. The scale ranged from grammatical (right, value 6) to ungrammatical (value 0), with ni l'un ni l'autre 'neither one nor the other' in the middle of the scale (value 3; Figure 1). Each participant evaluated all 96 items broken into two blocks, $\mathrm{A}$ and $\mathrm{B}$, each comprised of 48 items. One group of participants received the order $\mathrm{AB}$ and the other $\mathrm{BA}$, with the order of each block's items remaining the same. 


\begin{tabular}{|c|c|c|c|c|c|c|}
\hline $\begin{array}{c}\text { agrammatical } \\
0\end{array}$ & 1 & 2 & $\begin{array}{c}\text { ni l'un } \\
\text { ni l'autre } \\
3\end{array}$ & 4 & 5 & $\begin{array}{c}\text { grammatical } \\
6\end{array}$ \\
\hline $\mathrm{O}$ & 0 & 0 & 0 & 0 & 0 & $\mathrm{O}$ \\
\hline
\end{tabular}

The control fillers were divided into four groups. An example of each group is given in (11)-(14); see Appendix for a full list. For the factors Modals and Coordination, we picked the corresponding (un)grammatical counterpart of the test sentence. ${ }^{6}$

Grammatical control filler

Hier, je suis sorti de ma maison très vite.

Yesterday I am.IND left of my house very fast

'Yesterday, I got out of my house very quickly.'

a. Ungrammatical control filler (including obviation) * $\mathrm{Je}_{1}$ veux que je $\mathrm{j}_{1}$ parte

I want that I leave.SBJV

'I want (for) me to leave.' (Lit. 'I want that I leave.')

b. Ungrammatical control filler (without obviation)

*Je trouve être génial

I find be.INF brilliant

'I think I'm brilliant.' (Lit. 'I find to be brilliant.')

(13)

Grammatical control fillers for factor Modal

a. Infinitive (Ruwet 1991: ex. 41b)

(modal-type1)

Je veux pouvoir attaquer à l'aube.

I want can.INF attack to the.morning

'I want to be able to attack at dawn.'

b. Disjoint reference

Je veux que tu puisses partir demain.

I want that you can.SBJV leave tomorrow

'I want for you to be able to leave tomorrow.'

(14)

\section{Control fillers for factor Coordination}

a. Subject order: je-je-tu

*Je veux que je parte et que tu restes.

I want that I leave.SBJV and that you stay.SBJV

'I want for me to go and for you to stay.' (Lit. 'I want that I leave and that you stay.')

b. Subject order: je-tu-tu

(coord-type2)

Je veux que tu partes et que tu ne reviennes plus

I want that you leave.SBJV and that you NEG come.back.SBJV anymore

'I want you to leave and never come back.'

\subsubsection{Procedure}

The study was run on the online survey platform LimeSurvey in 2019. We distributed the link to our study via different social networks, email lists, and colleagues in France. Participants took between 15 and 30 minutes to complete the session. The survey began with a practice phase for familiarizing the participants with the survey. After this, participants started the official survey and evaluated the 96 test items. At the end, participants filled out a biographical questionnaire

5 Following Schütze (2016: 26f.) and his reasoning, we treat the terms acceptability judgment and grammaticality judgment as synonyms (see, e.g., Chomsky 1965:10-11; Sprouse et al. 2013: 220; Linzen \& Oseki 2018: 15; Juzek \& Häussler 2020: 134f. for a different view), and we distinguish between the terms grammaticality and acceptability only in cases in which it is important (e.g. when we speak of acceptable vs. grammatical sentences). In the introductory part of our experiment (see Appendix), we explained what we meant by the terms "(un)grammatical" to the participants in order to get intuitive, nonprescriptive judgments.

6 We do not have counterparts as control fillers for the other four factors (see Juzek \& Häussler 2020 for arguments for testing items independently of counterparts).
Feldhausen and Buchczyk

Glossa: a journal of

general linguistics

DOI: $10.5334 /$ gjgl.1219

Figure 1 Sample test item as displayed in the survey. ${ }^{5}$ 
consisting of questions about sex, age, educational background, profession, region of origin, other native languages spoken, age of onset, whether they had lived abroad for an extended period (and, if so, where), and their parents' native language(s) and region(s) of origin.

\subsubsection{Statistical analysis}

To establish whether there were significant differences in acceptability ratings between the different factors and between grammatical and ungrammatical filler sentences, we conducted a one-way ANOVA with Tukey's HSD post-hoc pairwise comparisons (see Appendix for the mean differences). Separate analyses for comparing sentences, including the factors Coordination and Modals, to their respective control fillers (see §4.1.2) were run. Following the same structure as for the overall analysis, those comparisons consisted of a one-way ANOVA with Tukey's HSD post-hoc pairwise comparisons. In both analyses, all other factors and non-matching filler sentences were excluded. All analyses were conducted with R version 4.0.4 (2021-02-15) (R Core Team, 2018) in Rstudio 1.4.1103, using the package tidyverse (Wickham et al. 2019). Figures were rendered in the same environment using ggplot (Wickham 2016).

Before analysis, we z-score transformed the results of the scale task (see Appendix for the raw values). To derive participant averages (each black dot in the violin plot) we averaged within-participants. For the mean ratings and standard deviations by factor (see Appendix), we calculated a grand average over the 87 participants.

\subsection{Results}

\subsubsection{Overall analysis}

Figure 2 presents violin plots of the z-score transformed rating for Ruwet's (1991) six factors across participants, while Figure 3 offers violin plots for the grammatical and ungrammatical control fillers. The overall analysis shows that there are significant differences in large effect sizes between the different factors and grammatical and ungrammatical filler sentences $\left(F(7,5473)=789.23, p<.001, \eta^{2}=0.50,95 \% C I[0.49,0.52]\right)$.

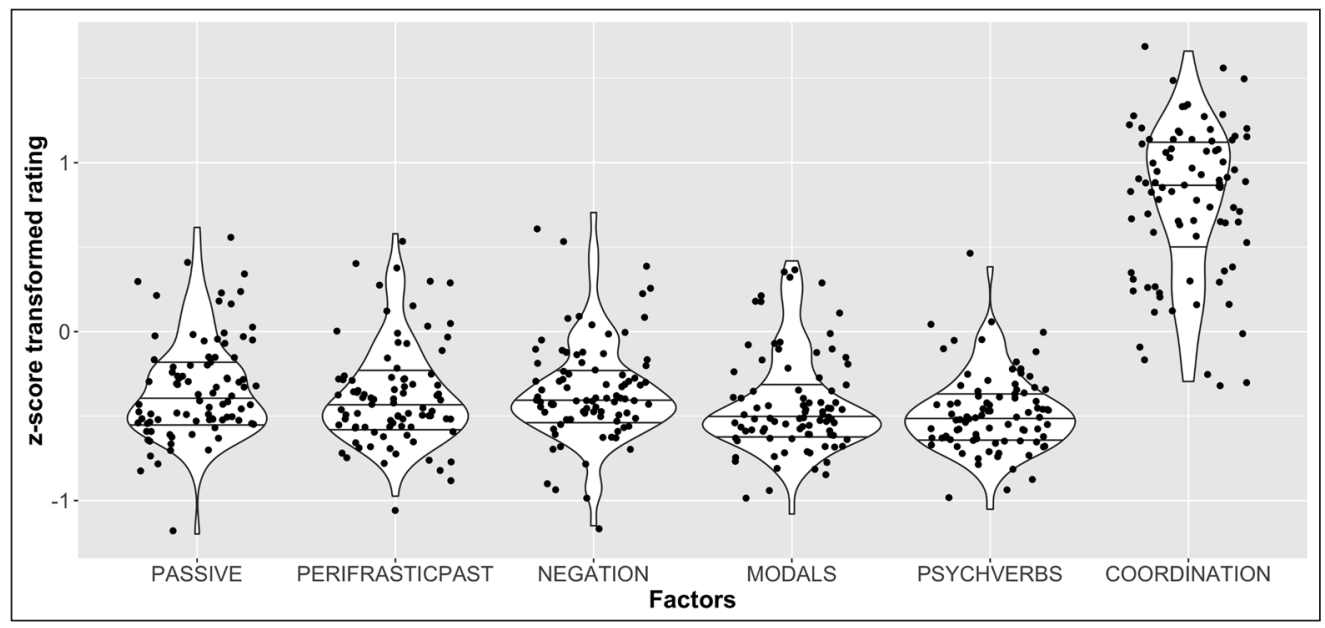

To test for differences between grammatical and ungrammatical fillers and the six different factors, we conducted planned comparisons using Tukey HSD. Ratings for ungrammatical control fillers (*-type1-obvi and *-type2) were significantly lower than those for grammatical control fillers (Diff $=-1.033,95 \%$ CI $[-2.053,-1.813], p<.001$ ), supporting the assumption that ratings reflected participants perception of acceptability, cf. Figure 3.

Average ratings of grammatical control fillers were significantly higher than those for test sentences in all categories (all diffs $>0.633, p s<.001$ ). This suggests that none of the factors are sufficient for native speakers to accept the test sentences as grammatical. As for ungrammatical control fillers, only the average ratings for sentences including the factors Modals $(\mathrm{M}=-0.430, \mathrm{SD}=0.292)$ and Psychverbs ( $\mathrm{M}=-0.488, \mathrm{SD}=0.226$ ) were not significantly higher than those for ungrammatical sentences (diffs $\leq 0.083$, $p s \geq 0.444$ ), suggesting that those factors did not significantly contribute to improving acceptability. In turn, the factors Coordination, Passive, PerifrasticPast, and Negation were all rated significantly higher than the ungrammatical sentences. Despite this, there is an
Feldhausen and Buchczyk Glossa: a journal of general linguistics DOI: 10.5334 /gjgl.1219
Figure 2 Violin plots of z-score transformed rating for Ruwet's (1991) six factors across participants; including median and quartiles. 


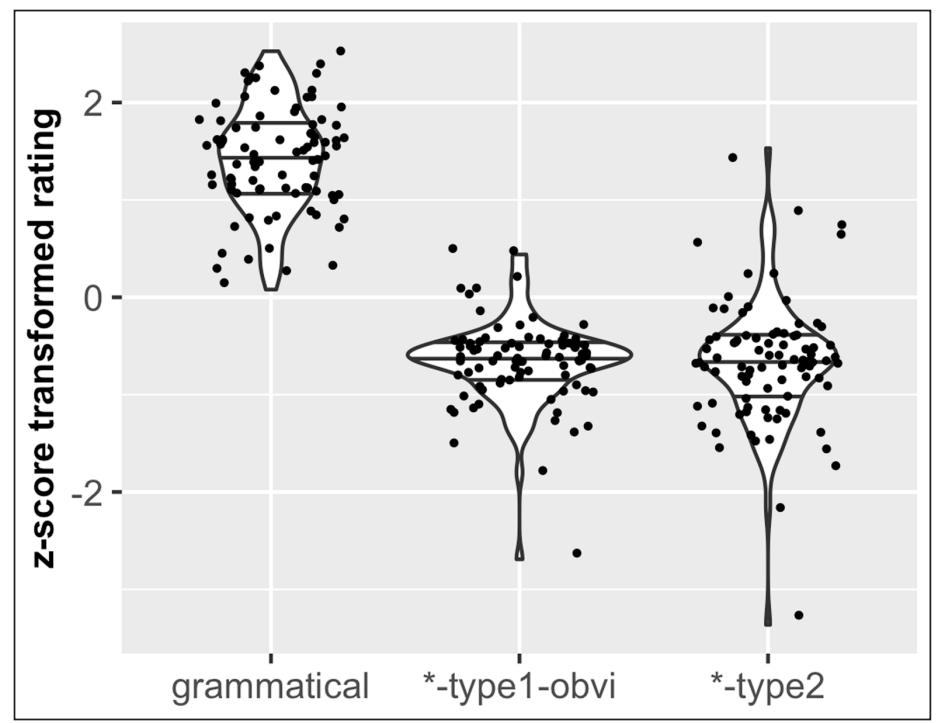

important difference among those four factors, with Coordination being rated significantly better than the rest: ratings for Coordination $(\mathrm{M}=0.786, \mathrm{SD}=0.449)$ were significantly higher than those for Passive ( $\mathrm{M}=-0.341, \mathrm{SD}=0.301$; Diff $=1.127,95 \%$ CI $[1.013,1.241] p=<.001$ ), suggesting that Coordination is considered much more acceptable by the participants. Since the difference between the two factors is smaller than the difference between Coordination and the other two factors, the latter differences are also significant (all $p s<.001$ ). In line with this, Figure 2 shows that the effect of the three factors Passive $(\mathrm{M}=-0.341, \mathrm{SD}=0.301)$, PerifrasticPast ( $\mathrm{M}=-0.376, \mathrm{SD}=0.291)$, and Negation $(\mathrm{M}=-0.361, \mathrm{SD}=0.302)$ is very small. The difference between the mean of these three factors $(M=-0.359)$ and the mean of the two factors Modals and Psychverbs ( $\mathrm{M}=-0.459$ ) adds up to 0.1 , suggesting that the effect cannot be interpreted in a meaningful way and may not be of practical relevance.

\subsubsection{Modals}

The analysis of the factor Modals (Figure 4) shows that there are significant differences of large effect sizes between test sentences including Modals and matched grammatical control fillers, including type 1 and $2\left(F(2,1041)=971.17, p<.001, \eta^{2}=0.65,95 \% C I[0.63,0.67]\right)$.

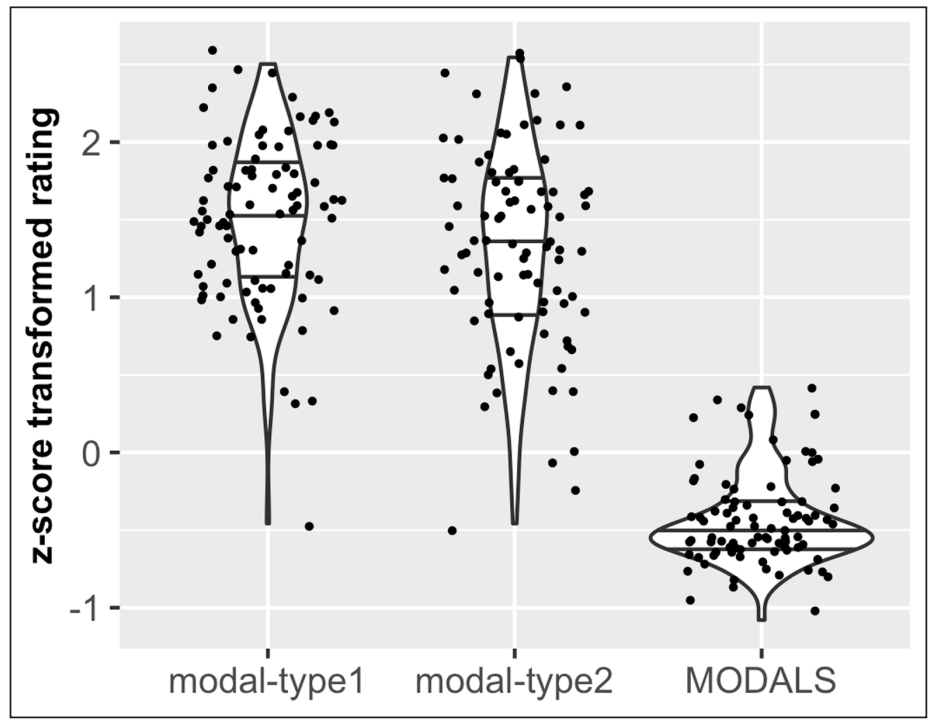

Pairwise comparisons revealed that test sentences including Modals were rated as significantly less acceptable than grammatical control fillers, including both the infinitive (type 1, Diff $=-1.932, p<.001$ ) and a switch of referent (type 2 , Diff $=-1.754, p<.001$ ). They also show a smaller, albeit significant, difference between type 2 and type 1 (Diff $=-0.178$, $p=.025$ ), where type 1 sentences are rated as more acceptable than type 2 sentences. This suggests that including Modals in an otherwise ungrammatical sentence does not suffice to approximate the acceptability of grammatical sentences.
Feldhausen and Buchczyk Glossa: a journal of general linguistics DOI: $10.5334 /$ gjgl.1219

Figure 3 Violin plots of z-score transformed rating for grammatical and ungrammatical control fillers (where ungrammatical $={ }^{*}$-type1obvi and *-type2); including median and quartiles.

Figure 4 Violin plots of z-score transformed rating for factor Modals and control fillers (modal-type 1 and modal-type2) across participants; including median and quartiles. 


\subsubsection{Coordination}

The analysis of the factor Coordination (Figure 5) shows that there are significant differences of large effect sizes between test sentences, including coordination and matched grammatical (coord-type2) and ungrammatical (coord-type1) control fillers $(F(2,1041)=177.97, p<.001$, $\eta^{2}=0.25$, 95\% CI[0.22,0.29]).

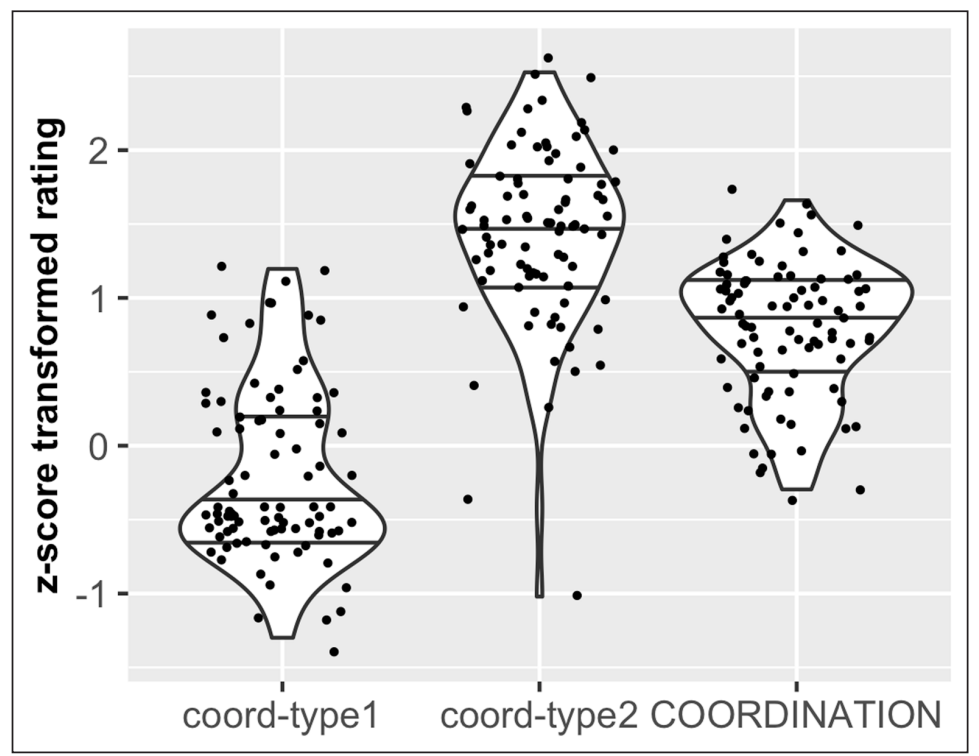

Tukey's HSD pairwise comparisons reveal that sentences with Coordination were rated as significantly more acceptable than parallel ungrammatical sentences (coord-type1, je-je-tu) (Diff $=-0.989, p<.001$ ) and as significantly less acceptable than parallel grammatical sentences (coord-type 2, je-tu-tu) (Diff $=0.644, p<.001$ ). This suggests that using Coordination in an otherwise ungrammatical sentence significantly increases acceptability, though acceptability still falls short of that of parallel grammatical sentences.

\subsubsection{Dialectal variation}

In our biographical questionnaire, we asked the participants about their origins in order to determine possible dialectal variation (distribution of participants per region: Hauts-de-France: $\mathrm{N}=27$; île-de-France: $\mathrm{N}=18$, Auvergne-Rhône-Alpes: $\mathrm{N}=12$; and others: $\mathrm{N}=30$ ). A non-parametrical Kruskal-Wallis test - applicable if more than two groups of a population are involved - shows no significant difference for dialect (Passive: $p=.412$; Periphrastic past: $p=.187$; Negation: $p=.068$; Modals: $p=.203$; Psych-verbs: $p=.207$; Coordination: $p=.223$ ).

\section{Discussion and conclusion}

\subsection{General discussion}

In endeavoring to answer our research question, we detected apparent differences between Ruwet's (1991) judgments of obviation weakening and our results. In particular, our study shows that (i) obviation weakening with respect to vouloir 'want' as the matrix verb does not appear to exist in the way previously suggested by Ruwet (1991), (ii) only je-tu-je-coordinations tend to weaken obviation convincingly, (iii) the role of agentivity does not seem to be as relevant to obviation as previously assumed, and (iv) dialectal variation is not attested as a contributor to obviation weakening in our (European) French data.

We do not conclude that obviation weakening per se should be called into question. Rather, our data indicate that the occurrence of obviation weakening cannot be taken for granted in the specific conditions presented here (i.e. in the context of vouloir 'want'). There are two reasons for this. First, looking at the individual results in our data, it seems some speakers judge the data similarly to Ruwet (e.g. participants 64 and 71 rated all 6 conditions (relatively) high and still rated ungrammatical control fillers low). It is unclear whether these are participants who truly experience weakening, or participants responding in some other way (a kind of noise). All we can know for sure is that the sample average is not consistent with weakening.
Feldhausen and Buchczyk Glossa: a journal of general linguistics DOI: 10.5334 /gjgl.1219

Figure 5 Violin plots of z-score transformed rating for factor Coordination and control fillers (coord-type1 and coord-type2) across participants; including median and quartiles. 
Determining how well each participant's rating reflects their grammar requires a different kind of study. The question arises as to whether Ruwet (1991) reports accurate reflections of his idiolect and whether he has a different idiolect than (most of) the participants in our study. Den Dikken et al. (2007) and Feldhausen (2016) highlight that averaging across multiple participants (as is standard in (psycho-)linguistic experiments) will obliterate individual differences. $^{7}$ The violin plots indicate variation in the participants' evaluations and reveal some outliers - evaluations that correspond to Ruwet's observations. Den Dikken et al. (2007) argue that individual judgments are highly relevant because they not only reflect the core idea of generative approaches - namely investigating the i-language of the individual/speaker hearer (p. 335) - but rather also allow for detecting micro-variants between different members of the same 'group' of language speakers (p. 339 \& 342). Following the same idea, Feldhausen (2016) suggests that the phenomenon of inter- and intra-speaker variation in the linguistic data of members of the same 'group' can be integrated into formal grammatical theory. In his approach, he proposes an underlying grammar for all speakers that reflects the sameness of the 'group' while providing options to allow for individual variation. Second, as demonstrated in $\S 2$ and $\S 3$, obviation weakening is a complex phenomenon. Since we only considered a subset of possible cases (namely the volitional verb vouloir 'want'), we cannot speak to the possibility of obviation weakening in other contexts.

If we are on the right track and if our results on obviation can be generalized, there are interesting implications for theories on obviation weakening: our study indicates that a theoretical approach of obviation weakening based on the role of agentivity is not necessary - at least for French. Since only the syntactic factor Coordination allows for obviation weakening, an analysis at the syntax-semantics interface (as proposed in Farkas 1992 or Constantini 2009 among others) seems to be no longer necessary, and it is therefore possible to reduce the theoretical apparatus used to account for obviation weakening. We refer the interested reader to Buchczyk \& Feldhausen (2020), where we propose a preliminary, novel syntactic analysis for the patterns attested here.

\subsection{Relation to the discussion on the reliability of acceptability judgment tasks}

The results of our study raise the question of how reliable the introspective data from Ruwet (1991) is. This directly relates to the ongoing discussion on whether informal methods are inherently reliable and whether the results of introspection can and should be replicated by formal acceptability judgment tasks. Some studies affirm the reliability of informal methods and highlight the importance of individual linguists' judgments (e.g. Phillips \& Lasnik 2003; Featherston 2009; Phillips 2010; Sprouse et al. 2013; Chen et al. 2020), while other studies deny, doubt or question that reliability (Langendoen et al. 1973; Schütze 2016 [1996]; Edelman \& Christiansen 2003; Gibson \& Fedorenko 2010; Gibson et al. 2013; Linzen \& Oseki 2018).

At first glance, our results seem to be in line with the latter group. However, it must be highlighted that our study was not designed to test the reliability of acceptability judgments for French generally; we merely tried to replicate a specific phenomenon. There are studies, in turn, that experimentally examined and confirmed the reliability of informal methods for a given language (English: Sprouse \& Almeida 2012, 2017; Sprouse et al. 2013; Korean: Song et al. 2014; Mandarin Chinese: Chen et al. 2020). We think it is worth conducting similar overarching studies on French to see whether its general pattern is like that of English, Korean, and Mandarin (especially since there are studies claiming differences between languages, e.g. Linzen \& Oseki 2018). ${ }^{8}$

If the former scholars are right, and no language differences influence reliability, how can our results be approached? Perhaps there is a difference between the general reliability of a given language established across different phenomena and the reliability of a specific, single phenomenon. Thus, while the general convergence rate for a given language is high, there might be some phenomenon where the convergence rate is low. Marantz (2005: 433ff.) and Linzen \& Oseki (2018: 3, 17f.) argue that so-called class 3 judgments build such a group of

\footnotetext{
7 We would like to thank Jon Sprouse (p.c.) for pointing out the issues of idiolect and averaging across multiple participants in the current context.

8 But see Chen et al. (2020: 313) for a critique of the method used by Linzen \& Oseki (2018).
}

Feldhausen and Buchczyk

Glossa: a journal of

general linguistics

DOI: 10.5334 /gjgl.1219 
complex and controversial data. ${ }^{9}$ Since coreference phenomena are explicitly mentioned to be part of class 3 judgments in Marantz (2005: 434), it is safe to say that obviation weakening can be put in this category. Further research on French in general and on obviation in particular might shed light on whether the phenomenon of obviation and/or French is a special case.

\subsection{Conclusion}

We hope that our formal method of collecting acceptability judgments has been demonstrated to be a promising and fruitful strategy for questioning long-standing informal results. Our study has shown that we were by and large unable to replicate Ruwet's observations concerning the weakening of obviation since only the factor Coordination convincingly increases acceptability in an otherwise ungrammatical sentence, challenging theoretical accounts of obviation weakening. As for the other five factors, an increase was either not detected or no meaningful interpretation could be made. Despite these results, we did not call obviation weakening per se into question since we considered only one type of matrix verb. We therefore hope that our theory-driven investigation of obviation opens the door to further research on this phenomenon, be it from an experimental or theoretical point of view. Looking beyond our study towards further experimental research, we believe that in addition to employing a formal acceptability judgment task, it would be intriguing to approach obviation weakening from different experimental and empirical angles, such as corpus studies or studies based on sociolinguistic interviews (e.g. Poplack 1992), which would allow for a consolidation of the results presented here and thus contributing to a better overall picture of the phenomenon of obviation weakening in French and other languages.

\section{Abbreviations}

1 = first person, $\mathrm{INF}=$ infinitive, $\mathrm{IND}=$ indicative, $\mathrm{NEG}=$ negation, $\mathrm{PL}=$ plural, $\mathrm{SG}=$ singular, SBJV = subjunctive

\section{Additional file}

The additional file for this article can be found as follows:

- Appendix. Structure and test items of the acceptability judgment study on obviation weakening in French. DOI: https://doi.org/10.5334/gjgl.1219.s1

\section{Acknowledgements}

We would like to thank the audiences at Going Romance 2019 and 2020, at the XXXVI biannual conference of the German Society of Romance Philology ("Romanistentag"; Kassel, 2019), and at the 45th conference Generative Grammar in the South (GGS, Frankfurt) as well as Nicole Dehé and the anonymous reviewers for their substantial comments and remarks that helped to improve the paper. We would also like to thank the native speakers of French who took pains to go through our experimental study. Without them, there would have been no paper. We are grateful to our colleagues who distributed the link to our survey to potential participants, too. Our sincere gratitude goes to both Cédric Patin for his constructive remarks while preparing our test items and to Jon Sprouse for his valuable comments on the statistical analysis and on our ideas of embedding the study in the discussion on the reliability of AJT. We would also like to express our profound thanks to Clara Huttenlauch and Annika Schiefner for their help with the statistics and plots. In addition, our thanks go to Markus Bader and Yvonne Portele for their help concerning the design and implementation of our experimental study. Audrey MacDougall, Robert Knowles, and Christopher Little dedicated their time and efforts to proofreading our English, and we are very thankful for their help. The entire team at Glossa likewise deserves our gratitude for their support and flexibility throughout the publication process. The first author would additionally like to thank Barbara Stiebels for introducing him to the world of obviation. All remaining mistakes are ours.
Feldhausen and Buchczyk

Glossa: a journal of

general linguistics

DOI: $10.5334 /$ gjgl.1219

.




\section{Competing interests}

The authors have no competing interests to declare.

\section{Author affiliations}

Ingo Feldhausen (D) orcid.org/0000-0002-5475-1630

ATILF-CNRS \& Université de Lorraine, 44, Avenue de la Libération, 54000 Nancy, FR

Sebastian Buchczyk (D) orcid.org/0000-0002-6740-8129

Universitat Pompeu Fabra, Roc Boronat, 138, 08018 Barcelona, ES

\section{References}

Bouchard, Denis. 1983. The avoid pronoun principle and the elsewhere principle. In Peter Sells \& Charles Jones (eds.), Proceedings of ALNE 13/NELS 13, 29-36. Amherst, MA: GLSA.

Bouchard, Denis. 1984. On the content of empty categories (Studies in Generative Grammar 14). Dordrecht: Foris.

Buchczyk, Sebastian \& Ingo Feldhausen. 2020. À propos du subjonctif en français: une révision expérimentale de l'effet de l'affaiblissement de l'obviation. $7^{e}$ Congrès Mondial de Linguistique Française/SHS Web of Conferences 78(14003). 1-14. [Please contact the authors for an English translation]. DOI: https://doi.org/10.1051/shsconf/20207814003

Chen, Zhong, Yuhang Xu \& Zhiguo Xie. 2020. Assessing introspective linguistic judgments quantitatively: the case of The Syntax of Chinese. Journal of East Asian Linguistics 29. 311-336. DOI: https://doi. org/10.1007/s10831-020-09210-y

Chomsky, Noam. 1965. Aspects of the theory of syntax. Cambridge, MA: MIT Press. DOI: https://doi. org/10.21236/AD0616323

Costantini, Francesco. 2005. On obviation in subjunctive clauses: the state of the art. Annali Di Ca'Foscari 44. 97-132.

Costantini, Francesco. 2009. Interface perspectives on clausal complementation: the case of subjunctive obviation. Venice: Libreria Editrice Cafoscarina.

Costantini, Francesco. 2013. Evidence for the competition-based analysis of subjunctive obviation from relative and adverbial clauses in Italian. In Sergio Baauw, Frank Drijkoningen, Luisa Meroni \& Manuela Pinto (eds.), Romance languages and linguistic theory 2011: selected papers from Going Romance Utrecht 2011, 75-92. Amsterdam: John Benjamins. DOI: https://doi.org/10.1075/rllt.5.04cos

Costantini, Francesco. 2016. Subject obviation as a semantic failure: a preliminary account. Annali di $\mathrm{Ca}^{\prime}$ Foscari 50. 109-131. DOI: https://doi.org/10.14277/2499-1562/AnnOc-50-16-5

Cuoq, Jean-André. 1866. Etudes philosophiques sur quelques langues sauvages de l'Amérique. Montréal: Dawson Brothers.

De Mulder, Walter. 2010. Mood in French. In Björn Rothstein \& Rolf Thieroff (eds.), Mood in the languages of Europe, 157-178. Amsterdam: John Benjamins. DOI: https://doi.org/10.1075/slcs.120.09dem

den Dikken, Marcel, Judy B. Bernstein, Christina Tortora \& Raffaella Zanuttini. 2007. Data and grammar: means and individuals. Theoretical Linguistics 33(3). 335-352. DOI: https://doi.org/10.1515/ TL.2007.022

Edelman, Shimon \& Morten H. Christiansen. 2003. How seriously should we take minimalist syntax? Trends in Cognitive Sciences 7(2). 60-61. DOI: https://doi.org/10.1016/S1364-6613(02)00045-1

Fanselow, Gisbert. 2007. Carrots - perfect as vegetables, but please not as a main dish. Theoretical Linguistics 33(3). 353-367. DOI: https://doi.org/10.1515/TL.2007.023

Farkas, Donka. 1992. On obviation. In Ivan Sag \& Anna Szabolcsi (eds.), Lexical matters, 85-109. Stanford: CSLI.

Featherston, Sam. 2006. Experimentell erhobene Grammatikalitätsurteile und ihre Bedeutung für die Syntaxtheorie. In Werner Kallmeyer \& Gisela Zifonun (eds.), Sprachkorpora: Datenmengen und Erkenntnisfortschritt, 49-69. Berlin: de Gruyter. DOI: https://doi.org/10.1515/9783110439083-005

Featherston, Sam. 2009. Relax, lean back, and be a linguist. Zeitschrift für Sprachwissenschaft 28(1). 127-132. DOI: https://doi.org/10.1515/ZFSW.2009.014

Feldhausen, Ingo. 2007. The relation of obviation and control: subjunctives and infinitives in Spanish. Berlin: ZAS manuscript.

Feldhausen, Ingo. 2010. Sentential form and prosodic structure of Catalan (Linguistik Aktuell/Linguistics Today 168). Amsterdam: John Benjamins. DOI: https://doi.org/10.1075/la.168

Feldhausen, Ingo. 2016. Inter-speaker variation, optimality theory and the prosody of clitic leftdislocations in Spanish. Probus 28(2). 293-334. DOI: https://doi.org/10.1515/probus-2015-0005

Giannakidou, Anastasia. 1997. The landscape of polarity items. Groningen: University of Groningen dissertation.
Feldhausen and Buchczyk

Glossa: a journal of

general linguistics

DOI: 10.5334 /gjgl.1219 
Giannakidou, Anastasia. 2009. The dependency of the subjunctive revisited: temporal semantics and polarity. Lingua 119. 1883-1908. DOI: https://doi.org/10.1016/j.lingua.2008.11.007

Gibson, Edward \& Evelina Fedorenko. 2010. Weak quantitative standards in linguistics research. Trends in Cognitive Sciences 14(6). 233-234. DOI: https://doi.org/10.1016/j.tics.2010.03.005

Gibson, Edward, Steven T. Piantadosi \& Evelina Fedorenko. 2013. Quantitative methods in syntax/semantics research: a response to Sprouse and Almeida (2013). Language and Cognitive Processes 28(3). 229-240. DOI: https://doi.org/10.1080/01690965.2012.704385

Giorgi, Alessandra \& Fabio Pianesi. 1997. Tense and aspect: from semantics to morphosyntax (Oxford Studies in Comparative Syntax). New York: Oxford University Press.

Gsell, Otto \& Ulrich Wandruszka. 1986. Der romanische Konjunktiv (Romanistische Arbeitshefte 26). Tübingen: Niemeyer. DOI: https://doi.org/10.1515/9783111372891

Juzek, Tom S. \& Jana Häussler. 2020. Data convergence in syntactic theory and the role of sentence pairs. Zeitschrift für Sprachwissenschaft 39(2). 109-147. DOI: https://doi.org/10.1515/zfs-2020-2008

Kempchinsky, Paula. 1987. The subjunctive disjoint reference effect. In Carol Neidle \& Rafael Nuñez Cedeño (eds.), Studies in Romance Languages, 123-140. Dordrecht: Foris. DOI: https://doi. org/10.1515/9783110846300.123

Kempchinsky, Paula. 2009. What can the subjunctive disjoint reference effect tell us about the subjunctive? Lingua 119(12). 1788-1810. DOI: https://doi.org/10.1016/j.lingua.2008.11.009

Langendoen, D. Terence, Nancy Kalish-Landon \& John Dore. 1973. Dative questions: a study in the relation of acceptability to grammaticality of an English sentence type. Cognition 2(4). 451-478. DOI: https://doi.org/10.1016/0010-0277(73)90004-8

Le Goffic, Pierre. 1993. Grammaire de la phrase française. Paris: Hachette Supérieur.

Linzen, Tal \& Yohei Oseki. 2018. The reliability of acceptability judgments across languages. Glossa: A Journal of General Linguistics 3(1). 100. 1-25. DOI: https://doi.org/10.5334/gjgl.528

Marantz, Alec. 2005. Generative linguistics within the cognitive neuroscience of language. The Linguistic Review 22(2-4). 429-445. DOI: https://doi.org/10.1515/tlir.2005.22.2-4.429

Mithun, Marianne. 1999. The languages of native North America (Cambridge Language Surveys). Cambridge: Cambridge University Press.

Mosegaard Hansen, Maj-Britt. 2016. The structure of modern standard French: a student grammar. Oxford: Oxford University Press.

Newmeyer, Frederick. 1983. Grammatical Theory: its limits and its possibilities. Chicago: University of Chicago Press.

Phillips, Collin. 2010. Should we impeach armchair linguists? Japanese/Korean Linguistics 17. 49-64.

Phillips, Collin \& Howard Lasnik. 2003. Linguistics and empirical evidence: reply to Edelman and Christiansen. Trends in Cognitive Sciences 7(2). 61-62. DOI: https://doi.org/10.1016/S13646613(02)00046-3

Picallo, Carme. 1985. Opaque domains. New York, NY: CUNY dissertation.

Poplack, Shana. 1992. The inherent variability of the French subjunctive. In Christiane Laeufer \& Terrell Morgan (eds.), Theoretical analyses in Romance linguistics, 235-263. Amsterdam: John Benjamins. DOI: https://doi.org/10.1075/cilt.74.17pop

Portner, Paul. 1997. The semantics of mood, complementation, and conversational force. Natural Language Semantics 5. 167-212. DOI: https://doi.org/10.1023/A:1008280630142

Quer, Josep. 1998. Mood at the interface. The Hague: Holland Academic Graphics.

Quer, Josep. 2001. Interpreting mood. Probus 13(1). 81-111. DOI: https://doi.org/10.1515/prbs.13.1.81

Quer, Josep. 2016. Mood. In Adam Ledgeway \& Martin Maiden (eds.), The Oxford guide to the Romance languages, 954-966. Oxford: Oxford University Press. DOI: https://doi.org/10.1093/acprof:o so/9780199677108.001.0001

Quer, Josep. 2017. Subjunctives. In Martin Everaert \& Henk van Riemsdijk (eds.), The Blackwell companion to syntax 2nd ed., 4278-4309. Oxford: Blackwell. DOI: https://doi. org/10.1002/9781118358733.wbsyncom113

Quer, Josep. 2020. The subjunctive. In Daniel Gutzmann, Lisa Matthewson, Cécile Meier, Hotze Rullmann, Thomas E. Zimmermann (eds.), The Wiley Blackwell companion to semantics, 1-28. New York, NY: Wiley. DOI: https://doi.org/10.1002/9781118788516.sem131

R Core Team. 2018. R: a language and environment for statistical computing. Vienna: R Foundation for Statistical Computing.

Raposo, Eduardo. 1985. Some asymmetries in the binding theory in Romance. The Linguistic Review 5. 75-110. DOI: https://doi.org/10.1515/tlir.1986.5.1.75

Riegel, Martin, Jean-Christophe Pellat \& René Rioul. 2014. Grammaire méthodique du français 5th ed. Paris: PUF.

Ruwet, Nicolas. 1991. Je veux partir/*Je veux que je parte: On the distribution of finite complements and infinitival complements in French. In John Goldsmith (ed.), Syntax and Human Experience. Chicago, IL: University of Chicago Press. [first published in: Cahiers de Grammaire 7 (1984), 75-138.]
Feldhausen and Buchczyk Glossa: a journal of general linguistics DOI: 10.5334 /gjgl.1219 
Schlenker, Philippe. 2005. The lazy Frenchman's approach to the subjunctive. In Twan Geerts, Ivo van Ginneken \& Haike Jacobs (eds.), Romance languages and linguistic theory 2003, 269-309. Amsterdam: John Benjamins. DOI: https://doi.org/10.1075/cilt.270.15sch

Schütze, Carson T. 2016. The empirical base of linguistics: grammaticality judgments and linguistic methodology (Classics in Linguistics 2). Berlin: Language Science Press. [first published in 1996, Chicago: University of Chicago Press.] DOI: https://doi.org/10.17169/langsci.b89.100

Schütze, Carson T. \& Jon Sprouse. 2013. Judgment data. In Robert Podesva \& Devyani Sharma (eds.), Research methods in linguistics, 27-50. New York, NY: Cambridge University Press. DOI: https://doi. org/10.1017/СВ09781139013734.004

Song, Sanghoun, Jae-Woong Choe, Eunjeong Oh. 2014. FAQ: do non-linguists share the same intuition as linguists? Language Research 50(2). 357-386.

Sprouse, Jon. 2018. Acceptability judgments and grammaticality, prospects and challenges. In Norbert Hornstein, Howard Lasnik, Pritty Patel-Grosz \& Charles Yang (eds.), Syntactic Structures after 60 years - the impact of the Chomskyan revolution in linguistics, 195-224. Berlin: De Gruyter. DOI: https://doi. org/10.1515/9781501506925-199

Sprouse, Jon, Carson T. Schütze \& Diogo Almeida. 2013. A comparison of informal and formal acceptability judgments using a random sample from Linguistic Inquiry 2001-2010. Lingua 134. 219-248. DOI: https://doi.org/10.1016/j.lingua.2013.07.002

Sprouse, Jon \& Diogo Almeida. 2012. Assessing the reliability of textbook data in syntax: Adger's Core Syntax. Journal of Linguistics 48(3). 609-652. DOI: https://doi.org/10.1017/S0022226712000011

Sprouse, Jon \& Diogo Almeida. 2017. Design sensitivity and statistical power in acceptability judgment experiments. Glossa: A Journal of General Linguistics 2(1). 1-32. DOI: https://doi.org/10.5334/gjgl.236

Stowell, Tim. 1993. The syntax of tense. Los Angeles: University of California manuscript.

Suñer, Margarita. 1986. On the referential properties of embedded finite clause subjects. In Ivonne Bordelois, Heles Contreras \& Karen Zagona (eds.), Generative studies in Spanish syntax, 183-196. Dordrecht: Foris. DOI: https://doi.org/10.1515/9783110859232-012

Szucsich, Luka. 2009. Obviation und temporale Abhängigkeit bei Subjunktiven. Zeitschrift für Slawistik 54(4). 398-415. DOI: https://doi.org/10.1524/slaw.2009.0027

Wickham, Hadley. 2016. ggplot2: elegant graphics for data analysis (Use R!) 2nd ed. New York: Springer. DOI: https://doi.org/10.1007/978-3-319-24277-4_9

Wickham, Hadley, Mara Averick, Jennifer Bryan, Winston Chang, Lucy D’Agostino McGowans, Romain François, Garrett Grolemund, Alex Hayes, Lionel Henry, Jim Hester, Max Kuhn, Thmas LinPedersen, Evan Miller, Stephan Milton Bache, Kirill Müller, Jeroen Ooms, David Robinson, Dana Paige Seidel, Vitalie Spinu, Kohske Takahashi, Davis Vaughan, Claus Wilke, Kara Woo \& Hiroaki Yutani. 2019. Welcome to the tidyverse. Journal of Open Source Software 4(43). 1686. DOI: https://doi. org/10.21105/joss.01686

Wiltschko, Martina. 2016. The essence of a category: lessons from the subjunctive. In Joanna Błaszczak, Anastasia Giannakidou, Dorota Klimek-Jankowska \& Krzysztof Migdalski (eds.), Mood, aspect, modality revisited, 218-254. Chicago: University of Chicago Press. DOI: https://doi. org/10.7208/9780226363660-007
Feldhausen and Buchczyk Glossa: a journal of general linguistics DOI: 10.5334 /gjgl.1219
TO CITE THIS ARTICLE:

Feldhausen, Ingo and Sebastian Buchczyk. 2021. Revisiting subjunctive obviation in French: a formal acceptability judgment study. Glossa: a journal of general linguistics 6(1): 59. 1-14. DOI: https://doi.org/10.5334/ gjgl.1219

Submitted: 09 February 2020 Accepted: 15 April 2021 Published: 05 May 2021

\section{COPYRIGHT:}

(c) 2021 The Author(s). This is an open-access article distributed under the terms of the Creative Commons Attribution 4.0 International License (CC-BY 4.0), which permits unrestricted use, distribution, and reproduction in any medium, provided the original author and source are credited. See http:// creativecommons.org/ licenses/by/4.0/.

Glossa: a journal of general linguistics is a peer-reviewed open access journal published by Ubiquity Press. 